\title{
Formation of Artistic Competence of Future Specialist of Decorative and Applied Art in the Field of Paper Plastic
}

\author{
Kovalchuk Tatyana Petrovna \\ Senior Lecturer of the Department of Theory and Methodology of Decorative \\ Arts, graphic arts and graphic faculty of the State institution "South Ukrainian \\ National Pedagogical University named after K. D. Ushinsky"
}

\begin{abstract}
The paper reveals the role of paperoplasty as the main method of modeling in creative workshops, which cannot be overstated. The importance of papyroplasty in the process of competence formation, as a system of means of artistic expression, which provides ample opportunity for the development and demonstration of the basics of the formal composition. It is emphasized that the architectonics of paper structures gives a special sound to the formal language of projects, which in turn influences the world of real things formed by artists, architects, sculptors, engineers. Paper compositions reveal the special logic of designing from sheet materials, therefore, in addition to artistic, also develops technical thinking.

The findings justify that paper is one of the most readily available materials to date, a tuning fork of independent creative pursuits and experiments. Accessibility, ease of use of paper serve as a guarantee of crystallization of three-dimensional spatial ideas, as this material gives wide possibilities for experimental searches. The properties of the material, its structural, shaping, and design capabilities determine the directions and conditions for the passage of such experimental activity. Shaping from paper implies a developed level of abstract thinking, which is required in artistic creativity and developing the discipline of paper science.
\end{abstract}

Keywords: paper, plastic, decorative art, competence.

Introduction. The concept of artistic and aesthetic education of students in secondary schools involves the solution of a number of problems, among which are the tasks of "formation of artistic competence - the ability to be guided by the acquired artistic knowledge and skills, the willingness to use ready-made experience in independent activity in accordance with universal universal values spiritual outlook. "

As a kind of decorative art, working with paper makes it possible to more actively develop aesthetic feelings and engage in transformative work according to the laws of beauty and harmony, to shape the need for artistic creativity.

Specificity of work with paper involves mastering the artistic means of creating decorative products, design, paper, design and other modeling techniques of paper and cardboard. Creativity in this field of artistic activity can be successfully developed only with the purposeful guidance of the teacher. Issues of didactic support for the process of teaching this type of art can be solved only by a teacher with a high level of methodological training. 
Recently, the importance of paper as fine material in decorative and applied, design, decorative art, in design and architectural modeling, due to the fact that paper is the most accessible artistic material, both in terms of simplicity in work and its value .

Techniques for the implementation of paper products have greater educational and educational opportunities. On the example of working with paper students learn a number of fine arts. In the course of artistic and labor activity they learn to analyze the phenomena and objects of the world around them, they develop imagination, arbitrary attention, compositional thinking, visual and figurative memory, a sense of rhythm, beauty of form, its spatial and structural features, color perception and its transformation. .

In the course of training, knowledge and skills in the field of stylization and generalization of real forms to figurative reproduction, organization of architectonics of flat and volumetric forms, their expressive harmony, which allows to master: from the initial sketch through full-scale sketches to the design of the design in the material; methods and techniques of decorative-plastic surface treatment of a sheet of paper; expressive means of product formation; compositional regularities of filling the surface of the sheet (the rhythmic organization of the image by the way of repetition and grouping of elements, objects by alternating elements close in shape, color, size); the concept of shape and its basic characteristics (proportions of the ratio of size, height and their influence on the figurative decision of the model, conditional structure and construction); basic concepts of spatial phenomena and their transfer on the plane and volumetric form in applied art, in design, as well as to form knowledge and skills in the field of color (the concept of dark and light colors, nuance and contrast, local, monochromatic, heterogeneous, related -contrast, additional colors, associative color rendering).

It must be constantly developed and improved in the continuous process of pedagogical practice. He must have a high level of artistic and pedagogical competence, that is, be able to teach students literacy and creative approach to the organization of educational process [1]. Thus, the real teacher-artist in the eyes of students emerges as the authoritative guide of the artistic picture of the world, an ideal model for imitation in the field of fine arts. Therefore, the development of artistic and creative competence is an important aspect in the work of a fine arts teacher. 
An analysis of recent research and publications indicates that many scholars have explored problems of creative and artistic competence. The theoretical positions of the competence approach are substantiated in the works of I. Bekh, L. Alekseeva, A. Bidenko, N. Bibik, T. Brage, I. Zazyun, I. Ermakova, O. Kononko, O. Ovcharuk, Rodrigina, O. Savchenko, A. Markova, A. Khutorsky and others. L. Masol, G. Padalka, O. Rostovsky, G. Sotska, O. Rudnitskaya, O. Shcholokova and others studied the professional competences of teachers of artistic disciplines. Instead, despite the considerable array of dissertation robits and publications on creative (O. Kaidanovskaya, S. Konovets, I. Muzhikova, G. Sotskaya, O. Music, O. Poddubna, L. Pokrovschuk, M. Stas, O. Stashuk and others) and artistic (L. Basanets, A. Marchenko, Y. Mohireva, I. Pastir, V. Shcherbina, etc.) aspects of the professional activity of the teacher of fine arts, the problem of forming his artistic and creative competence has not yet been the subject of separate study.

The purpose of the article is to determine the meaning, role and place of papyroplasty in the process of art training and to reveal the essence of artistic and creative competence of the future teacher of fine arts.

The main content (research methodology). Possessing fine techniques only at the reproductive level inhibits his creative thinking, limits the range of professional functions to the level of the consumer or translator of artistic values. Instead, the active embodiment of his ideas in the material of various types of fine arts enriches his artistic and aesthetic experience. Communication of students with the author's compositions of the teacher positively influences their motivation for creative activity, understanding of the spiritual and material world under the laws of beauty.

The main content (Discussion). In his research, P. Paidukov considers the professional competence of the future teacher of fine arts as an integrative and personal formation of the subject, which ensures his readiness for conscious and high-quality pedagogical and artistic activity, successful organization of art education of students. According to the researcher, its content includes such leading competencies as pedagogical, visual, design, research and reflexive [2, p. 5]. All of them in their unity attest to the most integrative category of artistic and aesthetic competence of a specialist in the field of art.

In their research, L. Masol and O. Haydamak interpret artistic competence as a certain experience of the individual in the field of art, the ability to co-organize in the field of artistic 
activity on the basis of value aesthetic orientations and to develop their own artistic and creative potential. According to scientists, this concept has a personality-activity and integrative character, as a multifaceted indicator of the effectiveness of art education and selfeducation, which integrates all components: content (knowledge), procedural (ability), axiological (values, orientation), self-realization (activity) ), creative (creativity) [3, p. 6].

Despite the fact that paper formations have existed for more than ten years, there is no direct use of the term "paper plastic" in the literature. Traditionally, the following terms have been used in theory: "paper plastics", "ornamental structure", "paper construction", "structural space with guide surfaces", "transformation of a flat sheet". Of course, the term "paper plastic" reflects both the artistic and creative features and the specifics of the genre itself, it is broader than just "the use of folded or other structures of paper in graphic design." With the introduction of this term, it becomes possible to historically build the evolution of paper as a material of modeling, the development of techniques and techniques of modeling, to show the continuity of the genre of experimental modeling. This term reflects the specifics of the author's approach to the study of compositional, structural, structural and technological laws.

The compositions themselves are not just samples of paper plastic, but also an analytical material that allows you to get into the basics of shaping patterns. This is a kind of modern "designer folklore", the secrets and techniques of which are transmitted directly in the process of live work and are the shaping baggage of art laboratories.

Paper-plastic as a system of means of artistic expression provides ample opportunities for mastering and demonstrating the foundations of a formal composition. Laws of rhythmic organization of form, principles of symmetry, dynamic fundamentals in the processing of folds of paper planes or in the formation of paper volume, understanding the elements of the composition as a single structural system, its combinatorial transformations, the series of software formations that integrate paper compositions into kinetic structures, The example of paper plastic is to discover the wide variety of compositional possibilities for sheet materials. Paper plastic is an intellectual asset of artistic modeling that allows you to find bright compositional solutions.

From our experience, it follows that the formation of artistic competence of future specialists of decorative and applied art in the field of paperoplasty is outlined as follows. In the empirical study of the formation of artistic and aesthetic competence of future teachers of 
fine arts, we relied on the criteria we have developed for the formation of artistic and aesthetic competence, taking into account that artistic and aesthetic competence is a holistic personal characteristic of a specialist in the field of artistic and pedagogical education in the components of unity: cognitive (knowledge of the content of competence in the form of facts, concepts, theories, technologies), motivational-value (reveals attitude to the content of artistic and aesthetic competence in the system of needs, motives, ideals, interests, values), activitypractical (experience of expression of artistic and aesthetic competence in various standard and non-standard situations), reflexive (emotional-volitional evaluation of the process and result of expression of artistic and aesthetic competence) aesthetic competence), personality development component (manifestations and development of personal qualities). In particular, we have defined the following criteria: epistemological, axiological, praxiological, autopsychological, creative. The epistemological criterion for the formation of artistic and aesthetic competence reflects the existence of a system of knowledge of the visual and decorative arts; the degree of development of artistic and pedagogical thinking, manifested in the combination of visual-figurative and theoretical thinking; Formation of perceptual, research, innovative skills; availability of a system of psychological and pedagogical knowledge regarding the organization of artistic and creative activity and aesthetic education. Axiological criterion takes into account the degree of awareness of artistic and aesthetic values, their importance for contemporary artistic, creative and educational activities; formation of needs for systematization and updating of artistic knowledge; Positive motivation for artistic and aesthetic activity; interest in arts and crafts; striving to solve problems on their own; attitude to decorative arts [1].

It is characteristic that the creative criterion reveals the possession of the techniques of personal expression and self-development in the sphere of artistic and aesthetic activity by means of decorative and applied art, techniques of self-realization and development of individuality within the profession (as an artist, as an educator); readiness for professional growth; persistence in achieving the set goals; ability for individual self-preservation, taking into account the specifics of artistic and aesthetic activity. To identify the state of formation of artistic and aesthetic competence of future teachers of fine arts and problems that arise in this process, we conducted a survey of students of different courses. According to the results of the questionnaire of students, we have made the following conclusions: in the classes of arts 
and crafts, sufficient attention is paid to the formation of motivational, value and activitypractical components of artistic and aesthetic competence of future teachers of fine arts; students point out enough different types of works used in traditional teaching, with the aim of stimulating and organizing practical activities in various techniques and types of decorative arts; the formation of the cognitive component due to the use of explanatory and illustrative teaching method plays a significant role in the teaching of arts and crafts; It is worrying that the practice of teachers of arts and crafts is not sufficiently used to systematically form the reflective and personal-developmental components of artistic and aesthetic competence of future teachers of fine arts.

Thus, the introduction of the technology developed by us for the formation of artistic and aesthetic competence of future teachers of fine arts contributed to their awareness of the importance of decorative and applied art for self-development as an artist and as a teacher, for their future professional activity, the development of a sense of artistic and aesthetic values, statements.

Conclusions. On the basis of the conducted research it is possible to draw the following generalizations and conclusions:

The development of paper formation involves the advanced level of abstract thinking that is required in artistic creativity and which, in turn, advances during the mastery of paper. Paper in the context of contemporary art and design becomes a kind of "instant response corps", a creative ground.

Paper plastics today is a promising area of design formation, which influences the development of project culture and arts and crafts. In this field, age-old experience is concluded, and yet, the creative potential of papyroplasty is not exhausted.

Paperoplasty is an intellectual asset of artistic modeling that allows you to find bright compositional solutions.

The essence of the artistic and creative competence of the teacher of fine arts, as his ability to continuously enrich his own visual experience, the development of aesthetic taste and special abilities, the completion of knowledge, the improvement of skills and skills of artistic shaping by means of composition in the practice of active production of original content and content value-added works, which becomes a solid foundation for achieving the pinnacle of artistic and pedagogical professionalism. 
Formation of artistic and aesthetic competence of future teachers of fine arts in the process of studying arts and crafts is effective in the implementation of technology of its formation, which involves the implementation of the following stages: value-oriented, informationcognitive, interpretive, reflexive, personal. We see further prospects in specifying the system of tasks offered at each stage of technology, taking into account regional peculiarities of national culture.

\section{References}

1. Kovalchuk, T.P., Reznichenko, N.I. (1998) Types of art work with paper: visual and methodological development. Odessa: Astroprint.

2. Paydukov, P. (2013) Formation of professional competence in future teachers of fine arts in the course of subject preparation: author's abstract of the dissertation. ... PhD and. ped. Sciences, special .: 13.00.08 / PV Pei-dukov. Cheboksary/ - 22 p.

3. Masol, L. M. (2010)Art Culture. Grade 10: Thematic development of lessons. The standard level. Academic level/ L. M. Masol, O.V. Gaidamaka. X.: The Morning Edition. - 336 p.

4. Vasercuk, Yu. (2007) A. Paperback in design culture of design / Julia Anatolyevna Vasercuk: Dissertation ... Candidate of Arts - 17.00.06. Moscow. - 194 p. 